\title{
Shaken baby syndrome resulting in death: a case series
}

\author{
Mucahit Oruç ${ }^{1 \oplus}$, Ahmet Sedat Dündar $^{1 \oplus}$, Hasan Okumuş ${ }^{2 \oplus}$, Mümine Görmez ${ }^{3 \oplus}$, \\ Emine Türkmen Şamdanc1 ${ }^{4}{ }^{\oplus}$, Osman Celbiş ${ }^{1 \oplus}$
}

Departments of ${ }^{1}$ Forensic Medicine and ${ }^{4}$ Medical Pathology, Inonu University Faculty of Medicine, Malatya; ${ }^{2}$ Council of Forensic Medicine, Malatya Group Administration, Malatya; ${ }^{3}$ Department of Medical Pathology, Tokat Gaziosmanpaşa University Faculty of Medicine, Tokat, Turkey.

\begin{abstract}
Background. The aim of this study was to raise the awareness of all healthcare personnel, primarily Emergency Department physicians, forensic physicians, and paediatricians about cases of shaken baby syndrome (SBS), which can be difficult to diagnose, require a high level of suspicion in diagnosis and there is a high likelihood of missed diagnosis.

Methods. A retrospective examination was made of 3400 forensic cases applied with autopsy between 2012 and 2018 to the Forensic Medicine Institution of Malatya Group Directorate.

Results. Of the total cases, 113 were aged $<2$ years and head trauma was determined in 35 . Eight cases were determined as SBS. Of the 8 cases that resulted in death, 75\% were male and the mean age was 8.3 months. The trauma had been perpetrated by the father in $50 \%$ of cases. There was a history of seizure in $67.5 \%$ of the infants and $75 \%$ were taken to the Emergency Department with cardiopulmonary arrest. Subdural hematoma and subarachnoid hemorrhage were determined in $37.5 \%$ of the cases, subdural hematoma, subarachnoid hemorrhage and intracranial hemorrhage in 50\%, and epidural hemorrhage and subarachnoid hemorrhage in $12.5 \%$. In the microscopic examination of the medulla spinalis, focal subdural fresh bleeding was seen in $50 \%$ of cases. Bleeding around the optic nerves was determined in $37.5 \%$ of cases bilaterally and in $37.5 \%$ unilaterally. Retinal hemorrhage was determined in all the cases, which was bilateral in $75 \%$.
\end{abstract}

Conclusions. The actual worldwide incidence of SBS is not known, and in Turkey, it is thought to be much higher than has been determined. The most important reason for this is thought to be that the diagnosis of child abuse is difficult and physicians do not have a sufficient level of knowledge.

Key words: shaken baby syndrome, autopsy, death.

One of the leading causes of death of physical abuse, which is a type of child abuse, is head trauma. ${ }^{1}$ Non-accidental head trauma in children is seen most often in the first year of life and is the most common cause of non-natural death in infancy. ${ }^{2}$ The sub-group of "shaken baby syndrome" (SBS) is the most frequently seen non-accidental head trauma in children. ${ }^{3}$ SBS is a specific type of child abuse in which the infant is held by the extremities or thoracic region and shaken, resulting primarily in

\footnotetext{
$\bowtie$ Ahmet Sedat Dündar

dr_asedat@hotmail.com
}

Received 12th May 2020, revised 2nd June 2020, accepted 20th June 2020. retinal bleeding, bone fractures, diffuse axonal damage, and subdural and subarachnoidal bleeding, through acceleration and deceleration mechanisms. ${ }^{3,4}$

Traumas causing rotation in the brain, as in abuse, usually cause severe and fatal injuries. Unlike adults, the brain is within a thin and elastic skull as ossification has not been completed. ${ }^{1}$ In a newborn, the brain constitutes $10 \%-15 \%$ of the body weight, whereas in adults it is $2 \%-3 \%$. The water content of the infant brain is high and myelin sheaths are thin and immature structures until the age of two years. ${ }^{1}$ Therefore, ruptures associated with trauma in immature brain tissue are more common 
than contusions. Particularly below the age of two years, the incomplete myelinisation and the short lengths of axons lay the ground for rupture. In addition, as the neck muscles are still weak, the brain is more exposed to acceleration and deceleration forces. ${ }^{5}$

The aim of this study was to create increased awareness of SBS in all healthcare personnel, but especially emergency department physicians, paediatricians, forensic physicians and forensic pathologist, in difficult-to-diagnose cases and those which are diagnosed and there is serious suspicion, where is a high probability of missing the diagnosis. The current study has the highest number of autopsy case series reported from Turkey.

\section{Material and Methods}

The study protocol was approved by the Institutional Ethics Committee of Inonu University and Malatya Group Forensic Medicine Institution (2018/3-19, 30.01.2018). Of the 3400 forensic cases whom autopsy was performed at the Forensic Medicine Institution of the Malatya Group Directorate between 1 January 2012 and 30 June 2018, 113 were identified as autopsies on infants under two years of age. From the evaluation of hospital records, histopathology examination reports, incident reports prepared by the police or armed forces, and witness and defendant statements, 35 cases of head trauma were identified. The cause of death of 8 of these 35 cases was determined as SBS.

These 8 cases were evaluated in respect to sociodemographic data, means of transport to the hospital, admission history, clinical findings, ophthalmic and intracranial injuries, and cause of death with histopathological examination.

\section{Results}

The examination was made of 8 cases that presented to the Emergency Department with findings of intracranial bleeding which resulted in death and were diagnosed with SBS following an autopsy. The cases comprised $6(75 \%)$ males and $2(25 \%)$ females. The age range of the cases ranged from 1.5 to 20 months and the mean age was 8.3 months. The trauma was inflicted on the infant by the father in $4(50 \%)$ cases, by the mother in $1(12.5 \%)$ case, and in $3(37.5 \%)$ cases, the perpetrator could not be determined. In 4 $(50 \%)$ cases, the infant suffered a seizure after the trauma, and there was a history of seizures in $5(67.5 \%)$ cases. It was determined that 6 (75\%) infants were brought to the Emergency Department with cardiopulmonary arrest. Of those who responded to resuscitation, 2 $(25 \%)$ were exitus following follow-up in the paediatric intensive care unit (ICU), 1 (12.5\%) in the paediatric surgical ICU, and of those with no history of arrest, $1(12.5 \%)$ was lost in the paediatric ICU and 1 (12.5\%) in the brain surgery ICU. With the imaging techniques applied, a linear bone fracture of the skull was determined in $2(25 \%)$ cases. Detailed information of the cases are given in Table I.

Classic autopsy was applied to the 8 cases evaluated. The histopathology samples (brain, cerebellum, medulla spinalis, lung, liver, kidney, heart and bilateral eyeballs with optic nerves) obtained during the autopsy were examined macroscopically and microscopically. The results showed subdural haemorrhage (SDH) and subarachnoid haemorrhage $(\mathrm{SAH})$ in 3 $(37.5 \%)$ cases intracerebral haemorrhage (ICH) together with SDH and SAH in $4(50 \%)$ cases, and epidural haemorrhage (EDH) and SAH in $1(12.5 \%)$ case. Microscopically focal subdural fresh bleeding was determined in $4(50 \%)$ cases of the medulla spinalis. The eyeballs and optic nerves were examined macroscopically and microscopically. Bleeding was determined around the optic nerve bilaterally in $3(37.5 \%)$ cases and unilaterally in $3(37.5 \%)$ cases, and no bleeding was determined in $2(25 \%)$ cases. Retinal bleeding was determined bilaterally in $6(75 \%)$ cases and unilaterally in $2(25 \%)$ cases (Figs. 1-4). 
Table I. Findings of the cases.

\begin{tabular}{|c|c|c|c|c|c|c|c|c|}
\hline Case No & 1 & 2 & 3 & 4 & 5 & 6 & 7 & 8 \\
\hline Age (months) & 1.5 & 4.5 & 20 & 1 & 13 & 13.5 & 1.5 & 11 \\
\hline Gender & M & M & M & M & M & $\mathrm{F}$ & M & $\mathrm{F}$ \\
\hline Perpetrator & Father & Father & Father & Unknown & Father & Unknown & Mother & Unknown \\
\hline Bone fracture & - & - & + & + & - & - & - & - \\
\hline Arrest at presentation & + & + & - & + & + & - & + & + \\
\hline Admission to the ICU & + & + & + & - & - & + & - & + \\
\hline Seizure after trauma & + & - & + & - & - & + & - & + \\
\hline \multirow{3}{*}{ Intracranial bleeding } & $\mathrm{ICH}$ & \multirow{3}{*}{$\begin{array}{l}\text { SDH } \\
\text { SAH }\end{array}$} & \multirow{3}{*}{$\begin{array}{l}\text { SDH } \\
\text { SAH }\end{array}$} & \multirow{3}{*}{$\begin{array}{l}\text { SDH } \\
\text { SAH }\end{array}$} & $\mathrm{ICH}$ & $\mathrm{ICH}$ & \multirow{3}{*}{$\begin{array}{l}\text { EDH } \\
\text { SAH }\end{array}$} & $\mathrm{ICH}$ \\
\hline & SDH & & & & SDH & SDH & & SDH \\
\hline & SAH & & & & SAH & SAH & & SAH \\
\hline $\begin{array}{l}\text { Bleeding around the } \\
\text { optic nerve }\end{array}$ & $+/+$ & $-/+$ & $-/-$ & $+/+$ & $-/+$ & $-/-$ & $+/+$ & $-/+$ \\
\hline Retinal haemorrhage & $+/+$ & $+/+$ & $+/+$ & $+/+$ & $+/+$ & $-/+$ & $+/+$ & $-/+$ \\
\hline $\begin{array}{l}\text { Injury in the medulla } \\
\text { spinalis }\end{array}$ & + & + & $\begin{array}{c}\text { No } \\
\text { sample }\end{array}$ & $\begin{array}{c}\text { No } \\
\text { sample }\end{array}$ & + & + & $\begin{array}{c}\text { No } \\
\text { sample }\end{array}$ & $\begin{array}{c}\text { No } \\
\text { sample }\end{array}$ \\
\hline
\end{tabular}

${ }^{*}$ M: male, F: female, ED: emergency department, ICU: intensive care unit, ICH: intracerebral haemorrhage, SDH: subdural haemorrhage, EDH: epidural haemorrhage, SAH: subarachnoid haemorrhage

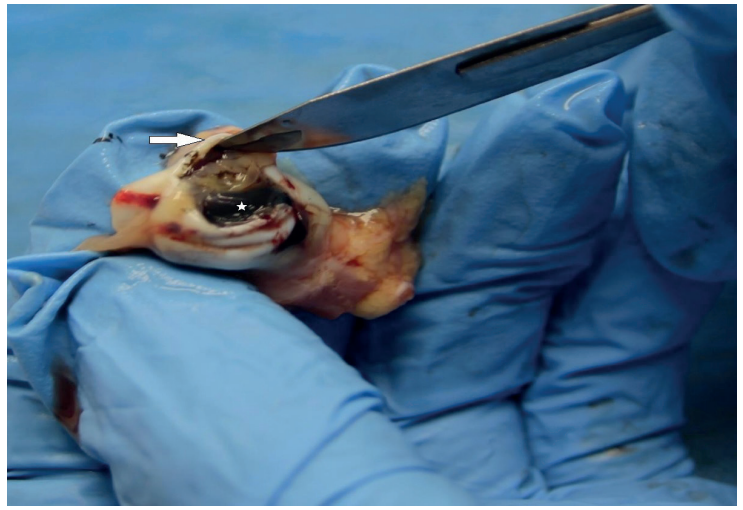

Fig. 1. The asterisk indicates retinal fresh hemorrhage and the arrow indicates the cornea.

\section{Discussion}

In the few studies on this subject, the incidence of SBS in infants aged under one year has been reported as $0.14-0.34 / 1000 .^{6-10}$ Although the incidence of SBS is known to be higher, the actual incidence is not fully known because of undiagnosed and misdiagnosed cases. ${ }^{6}$ Until 2001, there were no reported cases of SBS in Turkey, which can be attributed to insufficient identification of cases and non-reporting because of cultural reasons. ${ }^{11}$ The increase in SBS diagnosis in recent years is associated with greater awareness and sensitivity and the use of modern techniques. Of these, the evaluation of the medical and social history of the child, examination of the scene of the incident, correct evaluation of the macroscopic findings in autopsy and detailed histopathological evaluation are important. ${ }^{4}$

Head trauma in childhood is seen most often before the age of one year, and there is a currently increasing rate of SBS incidence reported as the cause of head trauma. ${ }^{1}$ Reports in the literature demonstrate that SBS is generally seen in infants aged under one year. Studies of cases diagnosed with SBS reported the mean age as 9 months in the USA, and as 4.2 months in a 10-year study in Canada. ${ }^{12-15}$ In the current study, the mean age was determined to be 8.3 months, which was consistent with findings in the literature.

Previous studies have reported the mortality rate of SBS cases as approximately $25 \%$ and death within a few days. ${ }^{2,3}$ In a study of 52 infants diagnosed with SBS, mortality was reported in 

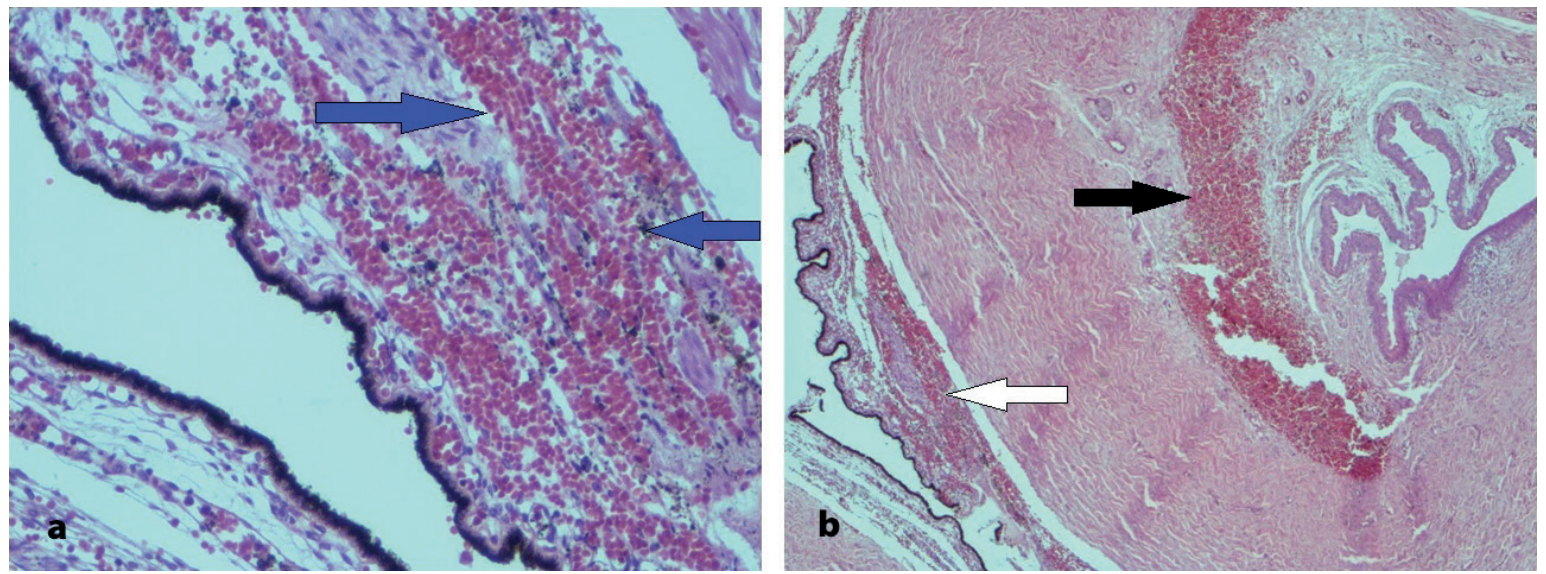

Fig. 2a. Fresh hemorrhage in the retinal layer of the eye (blue arrows). H\&E x100. b. Fresh hemorrhage area (black arrow) in the optic nerve and fresh hemorrhage focus (white arrow) in the retina adjacent to the optic nerve. $H \& E x 40$.

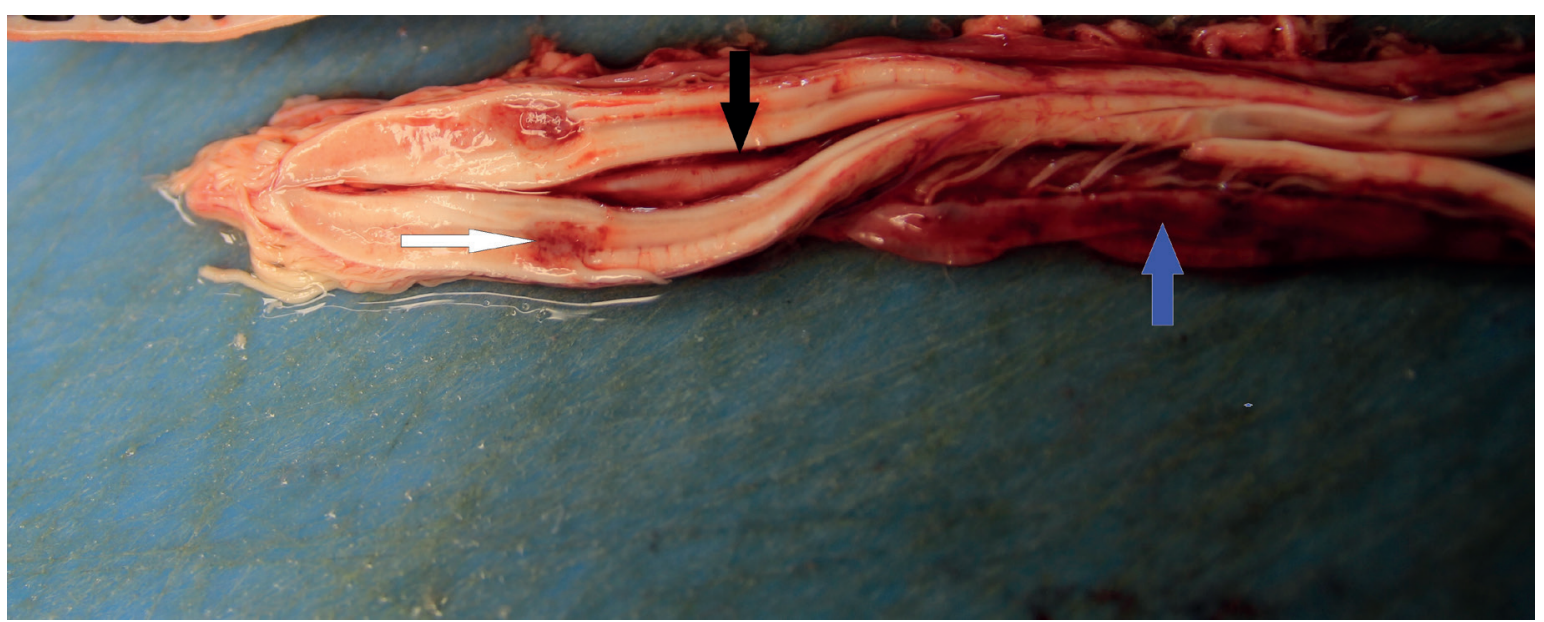

Fig. 3. Focal subdural fresh hemorrhage (blue arrow), focal paranchimal hemorrhage (white arrow) of medulla spinalis and bloody central canal fluid (black arrow).

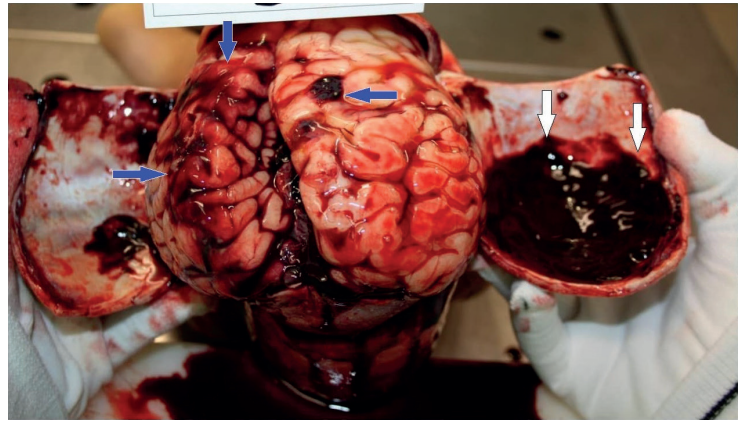

Fig. 4. Subdural fresh hemorrhage (white arrows) and subarachnoid fresh haemorrhage of left and right parietal lobes of brain (blue arrows).
$20(38.5 \%) .{ }^{16}$ It has also been reported that many cases are admitted to the hospital with a coma. ${ }^{17}$ In the current study, 6 (75\%) cases were brought to the Emergency Department with arrest, and $5(67.5 \%)$ had a history of ICU admission. The infants aged under one year were hospitalised because of cranial trauma, $65 \%$ were reported to be victims of child abuse. It was therefore stated that a detailed trauma history must be taken from the family and eyewitnesses. ${ }^{18}$ 
The parents of five SBS cases initially admitted having shaken the infant ${ }^{12}$ and in another study, the parents of five infants admitted shaking them in later interviews. ${ }^{17}$ In this study, when the recorded statements were examined, it was determined that $4(50 \%)$ infants had been shaken by the father, and $1(12.5 \%)$ by the mother.

Generally, SBS cases present at a healthcare centre, with no history of trauma, shaking, or falls, and presentation is with complaints of seizure, vomiting, a tendency for sleepiness, coma, respiratory problems, restlessness and poor breast suckling. ${ }^{12,18}$ Consistent with the literature, all cases in our study presented with complaints of seizure, vomiting, a tendency for sleepiness, coma, respiratory problems, restlessness or poor breast suckling. Yağmur et al. $^{11}$ reported that physical findings were determined in only 1 of 3 SBS cases, and Becker et al. ${ }^{17}$ determined physical findings in 2 of 5 infants diagnosed with SBS. Similarly, in the current study, physical findings were determined in $2(25 \%)$ of 8 cases.

Head trauma developing as a result of child abuse is seen up to the age of 4-5 years, and most often in infants below the age of one year. ${ }^{1}$ In childhood, the brain tissue is proportionally greater in the body and has a high water content, is located in a thin and elastic skull, the ossification of the skull is not complete, and sutures are not completely closed. ${ }^{1} \mathrm{SDH}$ is the most frequently seen intracranial bleeding and sometimes SAH may be seen alone or together with SDH in particular. ${ }^{17}$ A Canadian study of 364 cases diagnosed with SBS reported that 85\% were positive for SDH and in another study that evaluated child abuse cases with head trauma, SDH was determined at the rate of $80-85 \% .^{13}$ In a study of autopsies performed on children with head trauma as a result of abuse, subdural hematoma was determined in $90 \%{ }^{14}$ The histopathological examination of the current study cases showed subarachnoid bleeding in all the cases, $\mathrm{SDH}$ in $87.5 \%$, intracerebral haemorhage in $50 \%$ and epidural haemorrhage in $12.5 \%$.
In cases of SBS, as the optic disc and distal optic nerve are the regions most affected by tension and rupture forces, samples should be taken from these areas for histopathological examination. ${ }^{8}$ Retinal haemorrhage has been seen at the rate of $50 \%-100 \%$ in SBS cases, all layers of the retina are involved in the majority and have been reported as bilateral. ${ }^{7}$ Although the presence of subdural and retinal haemorrhage is pathognomic for the diagnosis of $\mathrm{SBS}^{20}$, only retinal haemorrhage can be determined. ${ }^{17}$ In addition, unilateral retinal haemorrhage, although rarely seen, should not be removed from the diagnosis, on the contrary, it greatly supports SBS diagnosis. ${ }^{15}$ Similarly in the current study, bleeding around the optic nerve was seen in $75 \%$ of the cases, unilateral in $37.5 \%$, and bilateral in $37.5 \%$. Retinal haemorrhage was seen in all the cases, bilaterally in $75 \%$ and unilaterally in $25 \%$.

SBS is a preventable problem. If it is not possible to reach the children before they have suffered shaking or other abuse, correct diagnosis and treatment with protective measures become important in the subsequent period. At the stage of diagnosis, it is important that a more detailed anamnesis, the necessary consultations and advanced tests are applied in all suspicious paediatric cases presenting at healthcare institutions, and especially in infants aged under two years. SBS must be considered in the differential diagnosis of infants aged under two years presenting with retinal bleeding, subdural hematoma and non-specific complaints. A diagnosis of abuse will prevent the child being sent home to be abused again and will provide protection for other children in the home.

The true incidence of SBS is still not known. In literature, extremely few SBS cases have been reported from Turkey compared to other developed countries in the world. The most important reasons for this are that healthcare personnel in Turkey do not have a sufficient level of knowledge to identify child abuse, and most cases presenting at the Emergency Department with head trauma or abuse are missed. Therefore, training of healthcare 
personnel in the diagnosis of these cases is of great importance. It is also vital in respect of preventative medicine that there is sufficient training and support on the subject of childcare for families of low socioeconomic status, primarily for parents.

It should be remembered that SBS may be present in pediatric patients who come with a history of nausea, vomiting, general condition and seizures. However, a family history that is incompatible with the physical examination findings should bring to mind this syndrome, which is already difficult to diagnose. The exaggerated and inconsistent attitudes of people who take care of the child (mother, father, babysitter) should be a warning for the physicians in terms of SBS. Parents who have exaggerated child love, which is common in our society and welcomed by all of us, should warn the doctor who examines the child of SBS. On the contrary, it should be noted that a SBS can be hidden under this condition. In the autopsies of infants, the diagnosis of SBS must not be forgotten. To be able to make a diagnosis in suspicious cases, correct macroscopic and microscopic evaluations should be supported by sampling.

\section{REFERENCES}

1. Case ME. Abusive head injuries in infants and young children. Leg Med (Tokyo) 2007; 9: 83-87.

2. American Academy of Pediatrics: Committee on Child Abuse and Neglect. Shaken baby syndrome: rotational cranial injuries-technical report. Pediatrics 2001; 108: 206-210.

3. Chiesa A, Duhaime AC. Abusive head trauma. Pediatr Clin North Am 2009; 56: 317-331.

4. Polat O. Fiziksel İstismar. (Polat Ed).) Tüm Boyutları ile Çocuk İstismarı (1. Cilt). Ankara: Seçkin Yayınları, 2007: 59-93.

5. Raghupathi R, Margulies SS. Traumatic axonal injury after closed head injury in the neonatal pig. J Neurotrauma 2002; 19: 843-853.

6. Minns RA, Jones PA, Mok JY. Incidence and demography of non-accidental head injury in southeast Scotland from a national database. Am J Prev Med 2008; 34(Suppl 4): 126-133.
7. Pollanen MS, Simth CR, Chiasson DA, Cairns JT, Young J. Fatal child abuse-maltreatment syndrome. A retrospective study in Ontario, Canada, 1990-1995. Forensic Sci Int 2002; 126: 101-104.

8. Gleckman AM, Evans RJ, Bell MD, Smith TW. Optic nerve damage in shaken baby syndrome: detection by beta-amyloid precursor protein immunohistochemistry. Arch Pathol Lab Med 2000; 124: 251-256.

9. Wygnanski-Jaffe $\mathrm{T}$, Levin AV, Shafiq A, et al. Postmortem orbital findings in shaken baby syndrome. Am J Ophthalmol 2006; 142: 233-240.

10. Kelly P, Farrant B. Shaken baby syndrome in New Zealand, 2000-2002. J Paediatr Child Health 2008; 44: 99-107.

11. Yagmur F, Asil H, Per H, Aslan D, Coskun A. Sarsılmış bebek sendromu \& 3 olgu sunumu. Adli T1p Dergisi 2010; 24: 42-49.

12. King WJ, MacKay M, Sirnick A; Canadian Shaken Baby Study Group. Shaken baby syndrome in Canada: clinical charecteristics and outcomes of hospital cases. CMAJ 2003; 168: 155-159.

13. Jenny C, Hymel KP, Ritzen A, Reinert SE, Hay TC. Analysis of missed cases of abusive head trauma. JAMA 1999; 281: 621-626.

14. Tzioumi D, Oates RK. Subdural hematomas in children under 2 years. Accidental or inflicted? A 10-years experience. Child Abuse Negl 1998; 22: 1105-1112.

15. Arlotti SA, Forbes BJ, Dias MS, Bonsall DJ. Unilateral retinal hemorrhages in shaken baby syndrome. J AAPOS 2007; 11: 175-178.

16. Brion D, Shelton D. Perparator accounts in infant abusive head trauma brought about by a shaking event. Child Abuse Negl 2009; 29: 1347-1358.

17. Becker JC, Liersch R, Tautz C, Schlueter B, Andler W. Shaken baby syndrome: report on four pairs of twins. Child Abuse Negl 1998; 22: 931-937.

18. Billmire ME, Myers PA. Serious head injury in infants: accident or abuse? Pediatrics 1985; 75: 340342.

19. Kirschner RH, Wilson H. Pathology of fatal abuse. In: Reece RM, Ludwing S (eds). (2nd ed). Child Abuse Medical Diagnosis \& Management. Philadelphia: Lippincott Williams\&Wilkins, 2001: 503-505.

20. Caffey J. On the theory and practice of shaking infants. Its potential residual effects of permanent brain damage and mental retardation. Am J Dis Child 1972; 124: 161-169. 